\title{
On the photo-induced electrical conduction related to gas sensing of the $\mathrm{Sb}: \mathrm{SnO}_{2} / \mathrm{TiO}_{2}$ heterostructure
}

\author{
Roberto A. Ramos Jr. ${ }^{\text {a,b,*, Miguel H. Boratto }}{ }^{c}$, Luis V.A. Scalvi ${ }^{a, b}$ \\ a São Paulo State University (UNESP), School of Sciences, POSMAT - Post-Graduate Program in Materials Science and Technology, Bauru, SP, 17033-360, \\ Brazil \\ b São Paulo State University (UNESP), School of Sciences, Department of Physics, Bauru, SP, 17033-360, Brazil \\ ${ }^{c}$ Federal University of Santa Catarina (UFSC), Department of Physics, Post-Graduate Program in Physics, Florianópolis, SC, 88040-900, Brazil
}

\section{A R T I C L E I N F O}

\section{Article history:}

Received 23 April 2018

Received in revised form 8 August 2018

Accepted 2 September 2018

Available online 8 September 2018

\section{Keywords:}

Tin dioxide

Titanium dioxide

Sensing properties

Photoconductivity

Electric-thermal influence

\begin{abstract}
A B S T R A C T
In this work, changes on the electrical properties as function of the temperature and gas addition on the surface of the $4 \mathrm{at} \% \mathrm{Sb}: \mathrm{SnO}_{2} / \mathrm{TiO}_{2}$ heterostructure are investigated. This heterojunction privileges the gas sensor application at temperatures nearer to the ambient temperature, when compared to existing devices, which is more efficient when sensitized with monochromatic light of specific wavelength. The results point that the conduction mechanism, under the thermally activated trapping influence, is occurring preferentially in the $\mathrm{TiO}_{2}$ layer, since the activation energy of the deepest level is 56 meV, comparable to donors from $\mathrm{TiO}_{2}$. Besides, an increase of the photo-current decaying rate was noticed when using the excitation of a He-Cd laser under $\mathrm{O}_{2}$ atmosphere and room temperature, compared to films with a sole $\mathrm{TiO}_{2}$ layer. Samples showed a high resistance variation (up to 40 times) with the addition of gas at temperatures higher than $330 \mathrm{~K}$, that can be attributed to the electron trapping by the oxygen molecules adsorbed on the sample surface. A model that describes such trap-states and the conduction mechanism within the samples is proposed. This way, this work can be valuable to the better understanding of the effects and rules on the electrical behavior of this heterostructure, in order to apply this material as a gas sensor device.
\end{abstract}

(C) 2018 Elsevier B.V. All rights reserved.

\section{Introduction}

Nowadays gas sensors based on semiconductors present growing interest [1-4] but have some disadvantages concerning the relatively high operating temperature and high power consumption [5]. To overcome such obstacles, several reports about the use of photoactivation of metal oxide semiconductor sensors have been published, in order to increase the gas sensitivity. Some of these works present the use of UV light to improve the gas sensitivity [4,6-8], and this illumination is an alternative to modulate and activate the sensor signal value [9]. On the other hand, the use of semiconductor heterostructures may improve even further the gas sensing properties, by means of the charge transfer from one material to another. Such heterostructures may also be improved through the UV illumination, by means of the creation of incom-

\footnotetext{
* Corresponding author at: São Paulo State University (UNESP), School of Sciences, POSMAT - Post-Graduate Program in Materials Science and Technology, Bauru, SP, 17033-360, Brazil.

E-mail address: roberto.ramos@unesp.br (R.A. Ramos Jr.).
}

plete bonding on the sensor's surface, enabling the adsorption of more gas molecules [10,11].

Interesting properties may be achieved from different heterostructures, and a very high variety of heterostructure applications have been reported in recent years, such as electrodes for supercapacitors [12], high energy density supercapacitors [13], and gas sensing devices [14-16]. In the case of gas sensor application, the formation of heterostructures enhances the sensing properties, as the use of $\mathrm{SnO}_{2}: \mathrm{Zn}_{2} \mathrm{SnO}_{4}$ nanowires (NW) [16] that causes an improvement of about 1.5 times in efficiency to sense ethanol, compared with sole $\mathrm{SnO}_{2} \mathrm{NW}$. Such improvement occurs in the principal mechanism for ethanol sensing [17], attributed to the dehydrogenation of ethanol with the addition of $\mathrm{Zn}_{2} \mathrm{SnO}_{4}$ to $\mathrm{SnO}_{2}$. The use of $\mathrm{n}-\mathrm{ZnO} / \mathrm{n}-\mathrm{In}_{2} \mathrm{O}_{3}$ presents up to 6 times improvement on methanol sensing compared to sole $\mathrm{In}_{2} \mathrm{O}_{3}$, ruled by the electron transfer effect at the heterostructure interface [15].

The junction of two materials forming a heterostructure creates a potential barrier at the interface, originated from the valence and conduction bands discontinuities of both semiconductors, after the thermodynamic equilibrium is reached [18]. The electrons tend to migrate from one material to another, according to the elec- 
tron affinity of the material [18,19]. Considering the $\mathrm{SnO}_{2} / \mathrm{TiO}_{2}$ (tin dioxide ( titanium dioxide) heterostructure, the equilibrium condition leads to electron transfer from the $\mathrm{SnO}_{2}$ to $\mathrm{TiO}_{2}$, due to the higher electron affinity of the $\mathrm{TiO}_{2}[18,20]$. The improvement of gas sensing properties in this heterostructure under illumination, compared to sole materials, occurs due to the photo-excitation of electrons in the exposed $\mathrm{TiO}_{2}$ layer, that along with the transferred electrons from the $\mathrm{SnO}_{2}$ layer, at the formation of the junction, increases the concentration of charges exposed on the surface, which act as adsorption centers for gas molecules [11]. The photoexcitation must be done by an UV-light source, with higher energy than $\mathrm{TiO}_{2}$ bandgap, and, after photo-excitation, electron transfer from $\mathrm{TiO}_{2}$ to $\mathrm{SnO}_{2}$ also may occur but due to the potential barrier at their interface this transference may be limited [10].

$\mathrm{TiO}_{2}$ is a semiconductor with wide bandgap of about $3.3 \mathrm{eV}$ [21]. The n-type conductive nature of $\mathrm{TiO}_{2}$ comes from interstitial $\mathrm{Ti}^{3+}$ and oxygen vacancies [22]. The presence of oxygen vacancies in this oxide facilitates the gas adsorption through stronger bonding between the film surface and the gas molecules, with desorption temperature of about $410 \mathrm{~K}$ [23,24]. Improved gas sensitivity of $\mathrm{TiO}_{2}$ can be achieved by growing the films in the (101) and (001) (hkl) planes of the anatase structure $[23,25,26]$. Tin dioxide $\left(\mathrm{SnO}_{2}\right)$ is also a wide bandgap semiconductor, that presents high transparency in the visible region, and high thermal stability $[27,28]$. The n-type conductivity nature of $\mathrm{SnO}_{2}$ also originates from oxygen vacancies and interstitial tin atoms [29]. Thin films obtained through sol-gel related techniques present low conductivity related to the small crystallites and consequently high grain boundary scattering that decreases considerably the electron mobility [30,31]. On the other hand, when donor-doped with $\mathrm{Sb}^{5+}$ ions an increase of electron density occurs in the semiconductor [31], which raises the conductivity.

In this work, the investigation of electrical characteristics of the $4 \mathrm{at} \% \mathrm{SnO}_{2} / \mathrm{TiO}_{2}$ heterojunction under photo-excitation is carried out at gas and room atmospheres. Different temperatures and their influences on the photo-induced decay rate are also evaluated and are related to deep level defects in the semiconductor layers. Concerning the improvement of the gas sensing properties, the illumination of the heterojunction, with well-established excitation energy, contributes to increase on the adsorption centers on the surface of the $\mathrm{TiO}_{2}$ exposed layer. The investigation presented in this work contributes to the understanding of the gas sensing mechanisms, and to the improvement in the $\mathrm{Sb}: \mathrm{SnO}_{2} / \mathrm{TiO}_{2}$ heterostructure under different atmospheres, temperatures and light excitation.

\section{Experimental details}

Sol-gel production of $\mathrm{TiO}_{2}$ was accomplished by hydrolysis and condensation of titanium (IV) isopropoxide using a high molar ratio of water:alkoxide (200:1), isopropanol as co-solvent, $\mathrm{HNO}_{3}$ as catalyst, and Triton X-100 as surfactant [32,33]. Initially $2.6 \mathrm{ml}$ of Nitric acid was added to $185 \mathrm{ml}$ of deionized water and $57 \mathrm{ml}$ of isopropanol, followed by dropwise addition of $15 \mathrm{ml}$ of titanium (IV) isopropoxide alkoxide, under stirring and heating at $85^{\circ} \mathrm{C}$ during 4 hours. The concentration of solution was performed by evaporating the solvent and dispersants at $100^{\circ} \mathrm{C}$ until reach a volume of $50 \mathrm{ml}$, which was followed by the addition of the surfactant under stirring for $30 \mathrm{~min}$. Colloidal suspension of 4 at\% $\mathrm{Sb}: \mathrm{SnO}_{2}$ was obtained through an aqueous solution of $\mathrm{Sn}^{4+}(0.5 \mathrm{M})$ obtained by dissolution of $\mathrm{SnCl}_{4} \cdot 5 \mathrm{H}_{2} \mathrm{O}$ in deionized water mixed to a solution of $\mathrm{Sb}$ obtained by dissolution of $\mathrm{SbF}_{3}$ in deionized water. Hydrolysis of $\mathrm{Sn}^{4+}$ and $\mathrm{Sb}^{5+}$ ions were promoted by addition of $\mathrm{NH}_{4} \mathrm{OH}$. The obtained suspension was submitted to dialysis against distilled water for elimination of chloride and fluoride ions [30,34].
The films depositions were carried out by dip-coating on soda lime substrate, previously cleaned with piranha solution at $\mathrm{H}_{2} \mathrm{SO}_{4}: \mathrm{H}_{2} \mathrm{O}_{2}$ ratio of $70: 30$, with immersion/emersion speed of $10 \mathrm{~cm} / \mathrm{min}$. The semiconductors films were obtained in a single deposition of each material. Firstly, the $4 \mathrm{at} \% \mathrm{Sb}: \mathrm{SnO}_{2}$ layer was deposited, followed by a calcination at $80^{\circ} \mathrm{C}$ for $10 \mathrm{~min}$, and a thermal annealing at $500^{\circ} \mathrm{C}$ for $2 \mathrm{~h}$. Then, the $\mathrm{TiO}_{2}$ was deposited, as the top layer semiconductor, with same calcination and annealing processes. The final thicknesses of these films are approximately $380 \mathrm{~nm}$ and $360 \mathrm{~nm}$, for $4 \mathrm{at} \%: \mathrm{SnO}_{2}$ and $\mathrm{TiO}_{2}$ respectively, as reported in a recent work with the same deposition parameters [35]. Aluminum electrodes were deposited paralelly on the $\mathrm{TiO}_{2}$ surface, using shadow masks, through thermal evaporation at pressure of about $10^{-6}$ torr. The thickness $(t)$ and width $(W)$ of $\mathrm{Al}$ deposited was $t=100 \mathrm{~nm}$ and $W=10 \mathrm{~mm}$, and length $(L)$ between electrodes $L=5 \mathrm{~mm}$. The final assembly of the sensor device is shown as inset of Fig. 2.

Structural, optical, and electrical characterizations were performed accordingly with the descriptions below. X-ray Diffraction (XRD) was carried out in a Rigaku diffractometer (Model D / Max 2100 / PC) operating with $C u K_{\alpha}$ radiation (1.5405 $\AA$ ) and Ni filter for attenuation of $K_{\beta}$ radiation and scanning rate of $2^{\circ} / \mathrm{min}$, in $2 \theta$ mode with fixed incident angle of $1.5^{\circ}$. Data were analyzed with the software Match (Crystal Impact), and the average crystallite size $(\tau)$ was estimated by Scherrer equation $\tau=K^{*} \lambda / \beta^{*} \cos (\theta)$, where $K$ is a shape factor with typical value of $0.9 ; \lambda$ is the wavelength of the $\mathrm{X}$-ray; $\beta$ is the broadening at half maximum intensity peak, and $\theta$ is the Bragg angle [30]. Optical transmittance and absorbance were performed in a Perkin Elmer spectrophotometer (Lambda Model 1050 UV / VIS / NIR) in the range 200-3300 nm. Photocurrent decay was performed under vacuum conditions in different temperatures $(120-300 \mathrm{~K})$, and under $\mathrm{O}_{2}$ atmosphere at room temperature. The photoexcitation was performed with He-Cd Laser, $\lambda=325 \mathrm{~nm}$ and power of $200 \mathrm{~mW}$, during $90 \mathrm{~s}$, with the laser beam directed to the region between electrodes. Although the laser energy is higher than the bandgap of both oxide semiconductors, it is inside the spectra region of high absorption of the $\mathrm{TiO}_{2}$ film (top layer) that works as a filter to higher energies than its bandgap. Therefore, most of the light energy is absorbed by this top layer and light with only energy lower than the $\mathrm{TiO}_{2}$ bandgap ( $3.3 \mathrm{eV}$ ) achieves the $\mathrm{Sb}: \mathrm{SnO}_{2}$ bottom layer, which is then, lower than its direct $(3.8 \mathrm{eV})$ bandgap. A fixed applied voltage $\mathrm{V}=2 \mathrm{~V}$ was set during the photoexcitation under room and $\mathrm{O}_{2}$ atmospheres. For measurements with $\mathrm{O}_{2}$ atmosphere, the gas was injected in the system at the end of the photoexcitation, to assure the same excitation conditions as under low pressure atmosphere.

\section{Results}

Results on structural and optical properties of the $\mathrm{Sb}: \mathrm{SnO}_{2} / \mathrm{TiO}_{2}$ film were obtained by XRD and UV-vis measurements, shown in Fig. 1, to obtain information about the optical properties and bandgap, as well as the crystalline phase and crystallite size of the sample. These properties are important factors that affect directly the electrical character in oxide semiconductors. The XRD presented in Fig. 1(a) shows that the most intense diffraction peak is attributed to plan (101) of anatase $\mathrm{TiO}_{2}$ (JCPDS-ICDD 2003, file \#089-4921). Although the thermal annealing occurred at $500^{\circ} \mathrm{C}$, which is below the necessary temperature for $\mathrm{TiO}_{2}$ anatase/rutile phase transition $[33,36]$, the figure shows diffraction peaks related to the planes (110) and (211) of $\mathrm{TiO}_{2}$ rutile phase (JCPDS-ICDD 2003 file \# 089-4920). In spite of the low thermal annealing temperature, $\mathrm{TiO}_{2}$ rutile phase may occur by two different mechanisms: the thermally activated transition phase, or the ordered structural induction. The first mechanism is associated with the formation of 

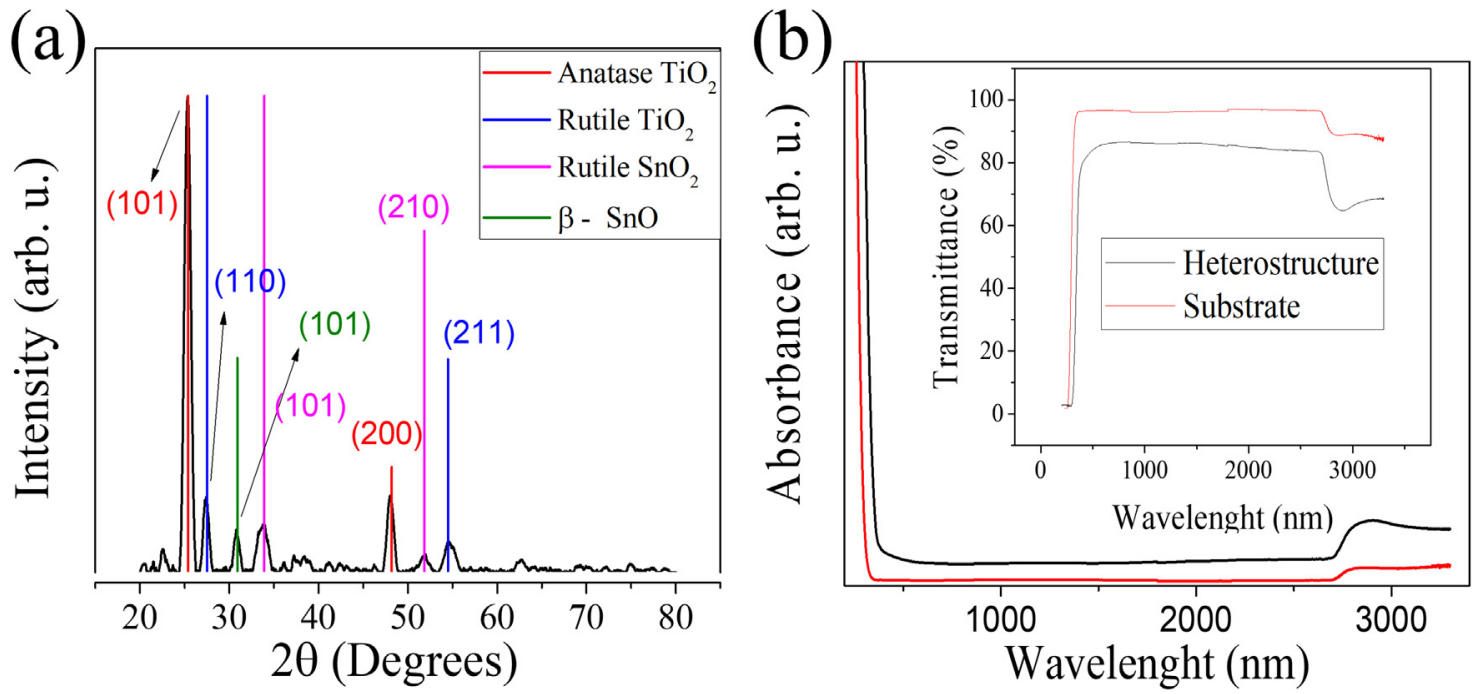

Fig. 1. (a) Diffractogram of the heterostructure film with the main diffraction peaks of $\mathrm{TiO}_{2}$ and $\mathrm{SnO}_{2}$. (b) UV-vis-Near IR optical absorbance, and transmittance (inset).

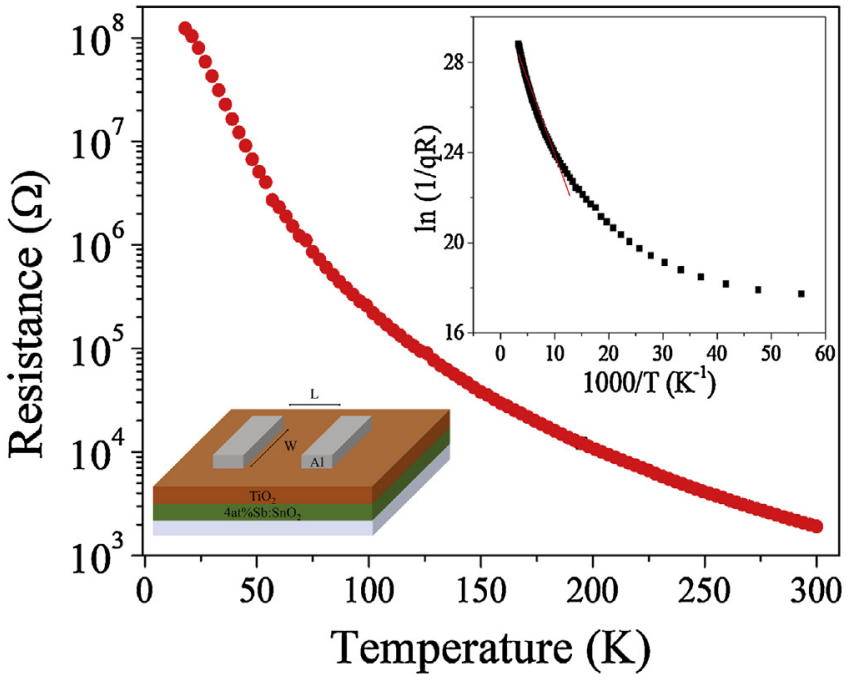

Fig. 2. Electrical resistance of the $\mathrm{Sb}: \mathrm{SnO}_{2} / \mathrm{TiO}_{2}$ as function of the temperature. Insets: (left) sample architecture, and (right) Arrhenius plot to estimate the activation energy of the deepest level in the sample.

rutile crystals in anatase grain boundaries [37], while the second mechanism is associated to the crystallization of the rutile $\mathrm{SnO}_{2}$ (JCPDS-ICDDD 2003 file \# 089-4920) bottom layer, that induces the arrangement of interfacial $\mathrm{TiO}_{2}$ in the rutile phase, to minimize mechanical stress at the interface. This interfacial stress reduction between the $\mathrm{SnO}_{2}$ and $\mathrm{TiO}_{2}$ semiconductor layers occurs due to only $5 \%$ mismatch on their lattice parameters, when both present rutile phase [38]. The rutile peaks of $\mathrm{TiO}_{2}$ presented lower intensities compared to its anatase peaks due to the probable growth of rutile $\mathrm{TiO}_{2}$ only at the interfacial region of the heterostructure. On the other hand, the rutile $\mathrm{SnO}_{2}$ presented low diffraction peak intensities due to its thinner layer caused by its dip-coating deposition with a less-viscous sol-gel suspension. The peak at $31^{\circ}$ is related to $\beta$ - SnO according to JCPDS-ICDD 2003 file 07-0195. As the intensity of this peak is relatively high, it is an indication that some regions of the $\mathrm{Sb}: \mathrm{SnO}_{2}$ film are non-stoichiometric.

Optical transmittance and absorbance on the UV-vis spectra is presented in Fig. 1(b). The $\mathrm{Sb}: \mathrm{SnO}_{2} / \mathrm{TiO}_{2}$ film shows high transmittance (about 90\%) which is expected, since high transmittance is also obtained for sole films of $\mathrm{TiO}_{2}$ and $\mathrm{Sb}: \mathrm{SnO}_{2}$ deposited by the same route, as demonstrated in previous reports, both above $80 \%$ [33,39].

Electrical characterization of the sample was carried out to evaluate the effect of temperature on the electrical resistance of the $\mathrm{Sb}: \mathrm{SnO}_{2} / \mathrm{TiO}_{2}$ film. The measurement was performed at low pressure $\left(10^{-3}\right.$ torr $)$ in a cryostat refrigerated with He-closed circuit, and the result obtained is presented in Fig. 2. It allows verifying that the resistance of the heterostructure film is highly dependent on the operation temperature, reaching 5 orders of magnitude from the lower resistance of $2 \times 10^{3} \Omega$ at $300 \mathrm{~K}$ to the higher resistance $10^{8} \Omega$ at $18 \mathrm{~K}$. The sample conductivity is expected to increase proportionally to the temperature due to higher concentration of free electrons released from defects from intrabandgap energy level as well as thermally generated intrinsic carriers. The release of electrons yields the free electron concentration on the conduction band as a function of the impurity energy level $\left(E_{a}\right)$ and temperature $(T)$ [40]. The activation energy of ionized level at room temperature can be calculated by plotting Arrhenius graph of conductivity as function of $T^{-1}$, as shown in the inset of Fig. 2, where the angular coefficient of the straight line is $-E_{a} / k$, where $k$ is the Boltzmann constant, yielding the impurity energy level.

The value of $E_{a}$ obtained for a short temperature range, near room temperature, refers to the defect with deepest energy level, which can capture electrons from the conduction band. The continuous inclination of the Arrhenius curve suggests that a continuous energy level distribution do exist in this sample. The range of activation energies of such levels may be taken from this graph and refer to the temperature-related energy to release trapped electrons.

The activation energy evaluated for higher temperatures is approximately $56 \mathrm{meV}$, similar to ionization of donor levels in rutile $\mathrm{TiO}_{2}$ (interstitial ions $\mathrm{Ti}^{3+}$ ) $[41,42]$. This agreement reinforces the partial anatase/rutile phase transition, and also implies that the electrical conduction occurs preferentially in the top $\mathrm{TiO}_{2}$ layer, rather than in the bottom $\mathrm{Sb}: \mathrm{SnO}_{2}$ layer. It is worth recalling that the absence of a sole straight line in the Arrhenius plot may be associated to multiple defects, which are common in oxide semiconductors [43]. These defects are progressively ionized with the increase of temperature and prevent the Arrhenius graph to be a straight line. Furthermore, the effective density of states and the mobility are not constants for a large temperature range, which implies that the deviation on the straight-line behavior in the Arrhenius plot is expected, as the temperature range becomes wider. 

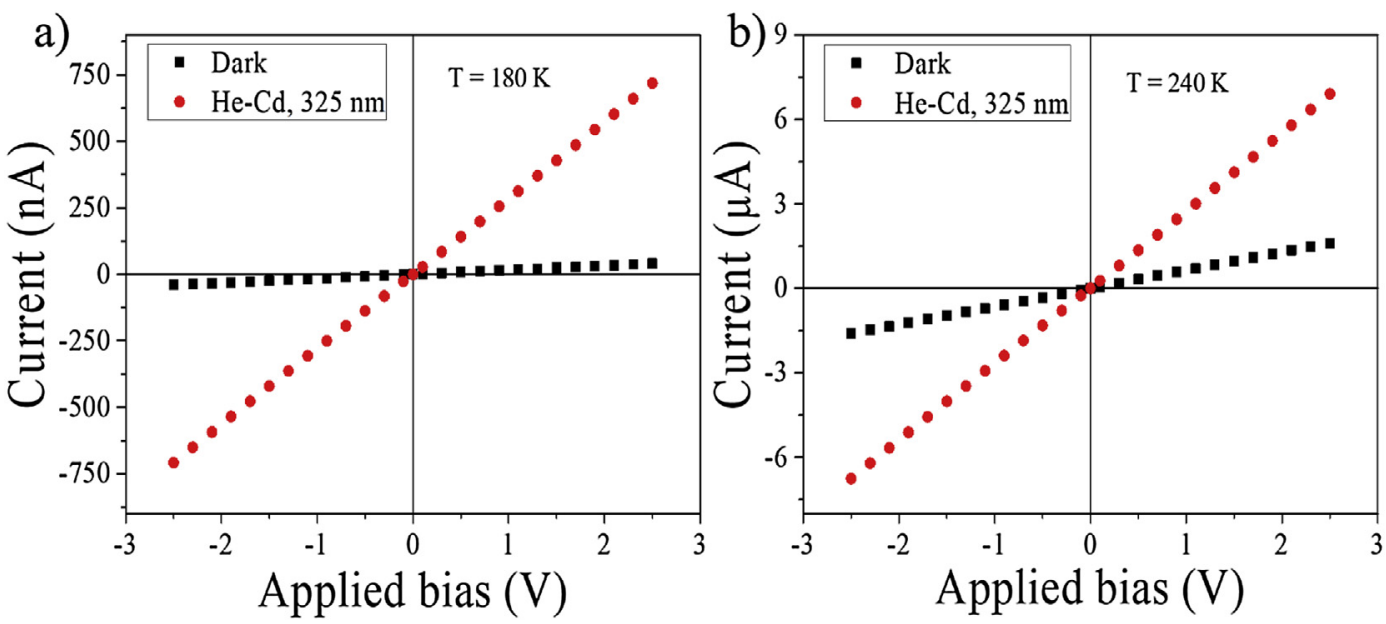

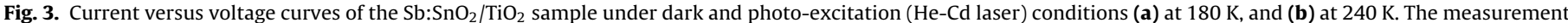
was performed under low pressure atmosphere $\left(10^{-3}\right.$ torr $)$.
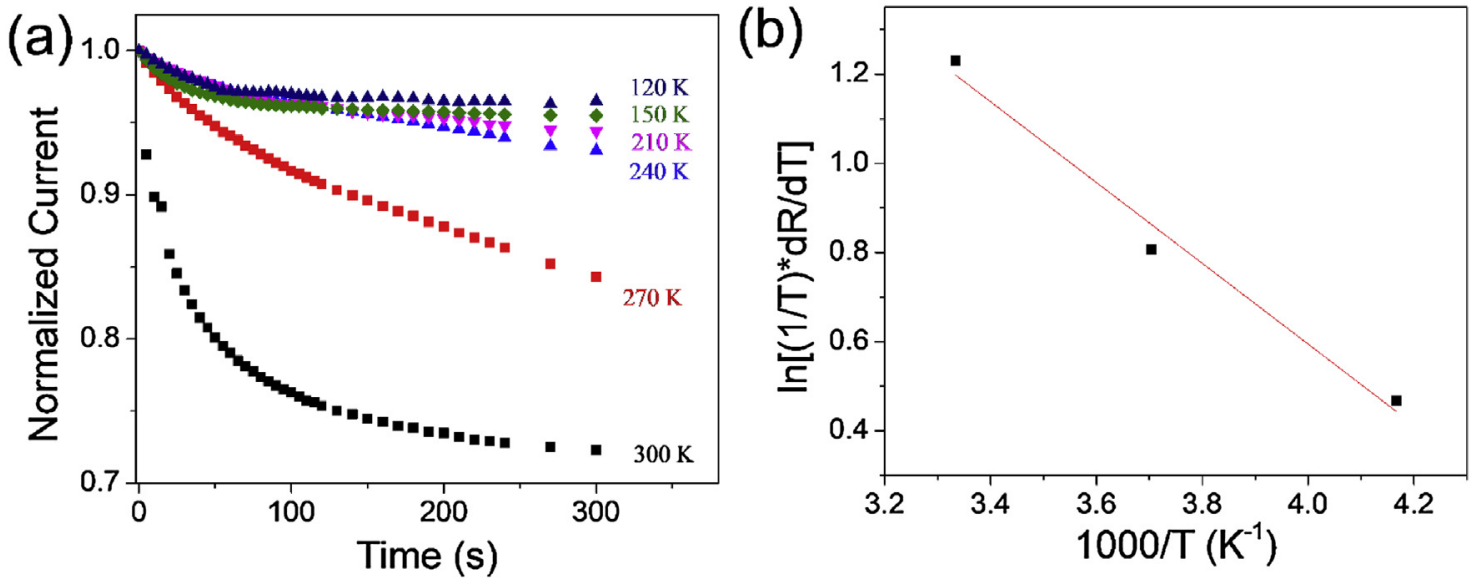

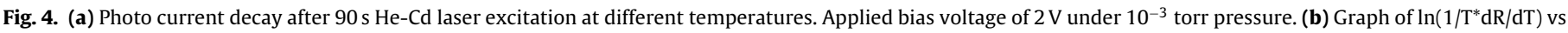
$1000 / \mathrm{T}$ for temperatures of $240 \mathrm{~K}, 270 \mathrm{~K}$, and $300 \mathrm{~K}$.

The electric behavior of the sample was also evaluated with respect to its dependence on the photo-excitation. In this measurement, the sample is irradiated with the He-Cd laser with wavelength of $325 \mathrm{~nm}(3.82 \mathrm{eV})$, under $20 \mathrm{~V}$ bias until the equilibrium was reached. This was done at two different temperatures, $180 \mathrm{~K}$ and $240 \mathrm{~K}$, as shown in Fig. 3(a) and (b), respectively. One can notice that the electrical resistance at $180 \mathrm{~K}$ is much higher as a result of the low thermal energy and the lower ionization of intrabandgap defects and intrinsic carriers, with influence on the electrons density in the conduction band, as previously discussed for Fig. 2. In both cases the resistance considerably decreases upon photo-excitation, compared to the dark values, showing values 17 times lower at $180 \mathrm{~K}$ (Fig. 3(a)), and 4 times lower at $240 \mathrm{~K}$ (Fig. 3(b)). These results demonstrate the sensibility of this heterojunction to light at different temperatures.

Hence the emission wavelength of the laser used for photoexcitation is in the spectral range with high optical absorbance of the sample, as previously shown Fig. 1(b), due to its energy higher than both materials bandgap energy, it could indicate that the electrical conduction enhancement rises mostly from the electronhole generation. Considering the same excitation conditions (e.g. power, time, pressure, and sample region) on both samples, the higher increase of electrical conductivity on the sample at $180 \mathrm{~K}$ may be associated to the higher electron mobility of the semiconducting layer where the conduction mainly occurs. Considering the domain of nanocrystallites in this sol gel oxide semiconductors; scattering by ionized impurities and phonons may be neglected, and the mobility becomes dominated by grain boundary scattering [44], which reduces at lower temperatures, consequently increasing both the mobility and electrical current under illumination, as the temperature falls down. The effect of mobility increase for reduced temperature has already been discussed for sole $\mathrm{Sb}: \mathrm{SnO}_{2}$ thin films [30].

As discussed above, the $\mathrm{Sb}: \mathrm{SnO}_{2} / \mathrm{TiO}_{2}$ semiconductor heterostructure present distinct sensibility to light at different temperatures, which led to the investigation of its photo-induced current decay for a temperature range. The chosen range was from $120 \mathrm{~K}$ to $300 \mathrm{~K}$, a wide range, in order to explore the more intense decay rate variations, and define the appropriate temperature interval, which could be used to evaluate sample kinetic parameters. This analysis helps understanding the rules of carrier retrapping in the current decay. The result is presented in Fig. 4, with the normalized current plotted as function of the time. Similar to the excitation of Fig. 3, the photo-excitation was accomplished with the He-Cd laser, but the irradiation time was $90 \mathrm{~s}$ under applied positive bias of $2 \mathrm{~V}$ on the sample, and the decay starting time $(t=0)$ occurred after turning the laser off. The decaying becomes slower at lower temperatures, as also found in $\mathrm{Er}: \mathrm{SnO}_{2}$ and $\mathrm{Eu}: \mathrm{SnO}_{2}$ samples $[44,45]$. The time-dependent decay means that the electrical resistance of the sample increases with 


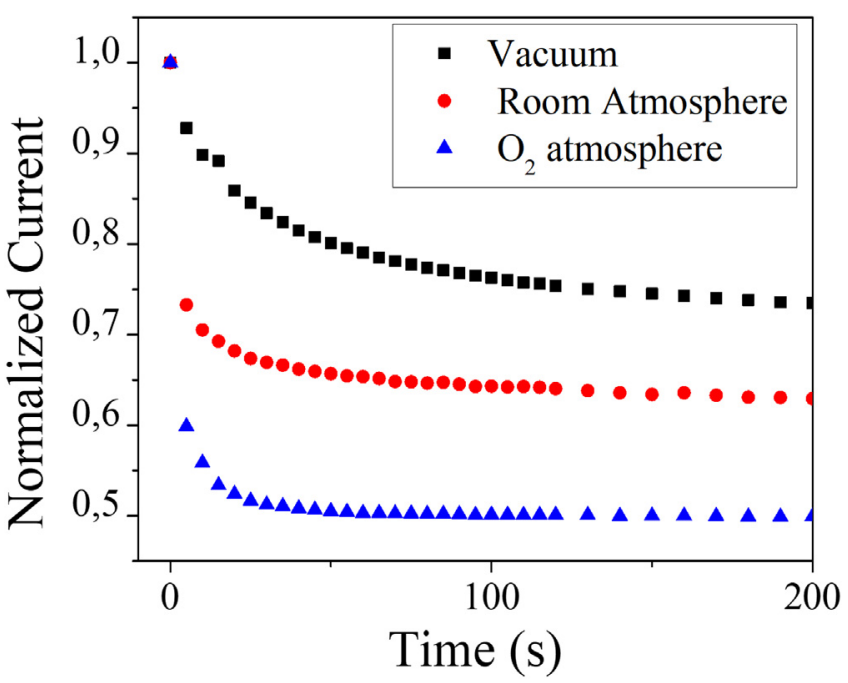

Fig. 5. Photo-induced current decay under different atmospheres $\left(10^{-3}\right.$ torr, room and $\mathrm{O}_{2}$-rich atmospheres) at room temperature ( $300 \mathrm{~K}$ ).

time through the recapture of electrons from the conduction band into trapping defects. It is important to recall that, when the heterostructure is being built, the presence of $4 \mathrm{at} \% \mathrm{Sb}: \mathrm{SnO}_{2}$ bottom layer supports the charge compensations, releasing charges into the $\mathrm{TiO}_{2}$, which leads to an increase of the sample conductivity. The decay rate, seen in Fig. 4(a), decreases drastically at lower temperatures, i.e. at $300 \mathrm{~K}$ the decaying current decreases about $26 \%$ of the initial value after $300 \mathrm{~s}$, while at $120 \mathrm{~K}$ the current decayed merely $4 \%$, a difference in the decay rate of 6 times. This is a positive result that implies that at higher operation temperatures the rate of trapping photo-generated charge carriers is also increased, increasing the efficiency of the sensor. As gas sensors usually operate at high temperatures (300-500 K), devices made from this heterostructure assembly may have its characteristics improved even further with light excitation.

The photo-induced decaying measurement can provide important parameters of the material related to dominant defects in the semiconductor. It was first proposed for investigating deep level defects in single crystalline MBE grown $\mathrm{Al}_{\mathrm{x}} \mathrm{Ga}_{1-\mathrm{x}}$ As [46], leading to the capture barriers $\left(E_{\text {cap }}\right)$ i.e. due to local relaxation of the lattice, around the trapping defect. The modification of this kinetics model for electron trapping in polycrystalline semiconductors was first applied to Er-doped $\mathrm{SnO}_{2}$ [44] yielding the potential barrier at grain boundaries $(\phi)$, besides the $\mathrm{E}_{\text {cap }}[30,44]$, since the sample polycrystalline nature imply in comparable relevance of the grain boundary potential barrier $(\phi)$ and the capture energy $\left(E_{\text {cap }}\right)$ for the conduc- tivity. Considering that the dominant effect on the heterostructure mobility is the grain boundary scattering, it can be shown that a plot of $\ln \left(1 / \mathrm{T}^{*} \mathrm{dR} / \mathrm{dt}\right)$ versus $1 / \mathrm{T}$ yields the $\left(\mathrm{E}_{\mathrm{cap}}-\phi\right)$ directly from the curve slope, as presented in Fig. 4(b). dR/dT is the inclination of the time dependent resistance for the first $50 \mathrm{~s}$ of decay, evaluated for each temperature $[30,44]$. As the curves starts to superimpose each other below $240 \mathrm{~K}$, we may consider with reliability the measures above this temperature for the evaluation of $\left(E_{\text {cap }}-\phi\right)$. The average slope of the fitting line of the data presented in Fig. 4(b) yields the value of $\left(\mathrm{E}_{\mathrm{cap}}-\phi\right)=78 \pm 11 \mathrm{meV}$. The temperature range $(240-300 \mathrm{~K})$ for the evaluation of photo-induced decay parameters is in good agreement with previous publications [20,34,35]. For a wider range, other defects may become relevant for the trapping process and compete for electron capture, leading to the overlap of the decay curves, as observed. This result is also in good agreement with the Arrhenius plot (inset of Fig. 2), that reveals a distribution of defect levels with distinct energies, meaning a sample with multiple defects.

As already discussed, the conduction occurs preferentially in the $\mathrm{TiO}_{2}$ layer, according to the evaluated sample activation energy and the architecture itself (inset of Fig. 2). Then, the potential barrier height in grain boundaries of the titanium oxide layer can be given as $\phi=89 \pm 30 \mathrm{meV}$ [48], value obtained from a sample with the closest stoichiometry to the $\mathrm{TiO}_{2}$ layer considered here. In this way, the capture energy for the heterostructure, calculated from the curve slope of Fig. 4(b) is $E_{c a p}=167 \pm 10 \mathrm{meV}$. The capture energy means the lattice relaxation around the defect for the trapping process, usually originated from the ion local movement [49]. The obtained value is a rather high, and a good indicator of a large lattice relaxation process. It is also in very good agreement with the value obtained for the capture energy in 4at\%Er-doped $\mathrm{SnO}_{2}$ films [44]. The capture energy found in that work was associated with the ionization levels of oxygen vacancies, whose exact lattice relaxation mechanism is worthy of further investigation, but not in the scope of this paper. It is also important to mention that $\mathrm{E}_{\text {cap }}$ is different from the value that would be obtained for the ionization energy, or energy difference between the defect level and the conduction band bottom [47]. Then, it is not expected that reported values for vacancies ionization, e.g. 320 and $500 \mathrm{meV}$, for the first and second ionization levels [50] agree with the $\mathrm{E}_{\mathrm{cap}}$ value obtained in the present work. However, the magnitude of these defects levels, quite deep in the bandgap, assures that some sort of lattice relaxation must be expected.

The electrical characteristics of the heterostructure sample were also investigated by photo-decaying current under different atmospheres at room temperature $(300 \mathrm{~K})$.Considering the difficulties in controlling the temperature under non-vacuum condition, the experiment was run only at room temperature. Fig. 5 shows the (a)

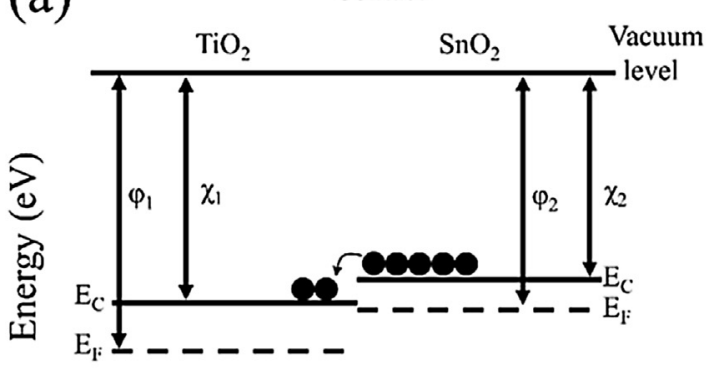

(b)
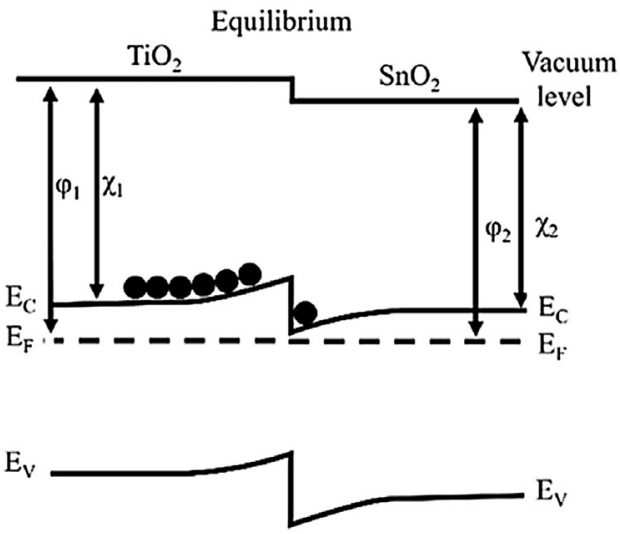

Fig. 6. Band diagrams of the junction between $\mathrm{TiO}_{2}$ and $\mathrm{Sb}: \mathrm{SnO}_{2}$ (a) prior and (b) after equilibrium is achieved. 
photo-induced current obtained. The excitation was similar to the temperature-dependent measurement, with irradiation with He$\mathrm{Cd}$ laser during $90 \mathrm{~s}$ under applied bias voltage of $2 \mathrm{~V}$ under vacuum, to ensure that the sample was excited under the same conditions. When the excitation time was achieved, the gas was injected into the cryostat concomitant with the excitation removal and starting decaying time $\mathrm{t}=0 \mathrm{~s}$.

The decaying current-rate increases sharply at higher $\mathrm{O}_{2}$ concentration, as can be seen after the injection of room atmosphere gas, that causes an abrupt decay on the first $20 \mathrm{~s}$ of measurement, that is further increased under $\mathrm{O}_{2}$-rich atmosphere. Under room atmosphere $\left(\mathrm{O}_{2}\right.$ concentration of about 20\% [51]), the current decays $25 \%$ in the first $5 \mathrm{~s}$, while under the $\mathrm{O}_{2}$-rich atmosphere (99,995\% pure) the current decays almost $40 \%$ on the same time interval. After the abrupt current fall in the first seconds, the current decay becomes slower in all the three atmospheres. This abrupt decaying current rate did not occur in sole $\mathrm{TiO}_{2}$ film measured under similar conditions as reported in a previous work [35], which implies that the interface between $\mathrm{TiO}_{2}$ and $\mathrm{Sb}: \mathrm{SnO}_{2}$ of the heterostructure is contributing to the higher gas-sensing on the sample. Under excitation, the gas-adsorption improvement on the $\mathrm{TiO}_{2}$ surface may occur due to the increase of electrons in the $\mathrm{TiO}_{2}$ layer coming from excitation and from the $\mathrm{SnO}_{2}$ layer. Fig. 6 presents the band diagrams of the semiconductors under contact and thermodynamic equilibrium. This diagram was built considering the vacuum level as reference $(E=0)$ and the values reported in literature of $4.6 \mathrm{eV}[11,20]$ and $4.2 \mathrm{eV}[11,52]$ for electron affinity $(\chi)$, and $5.5 \mathrm{eV}[53,54]$ and $4.5 \mathrm{eV}[52,55-57]$ for work function $(\varphi)$ of the anatase $\mathrm{TiO}_{2}$ and rutile $\mathrm{SnO}_{2}$, respectively, as well as previous reported band diagrams of $\mathrm{TiO}_{2} / \mathrm{SnO}_{2}$ heterostructure [11]. The discontinuity of the conduction band is reported as $0.62 \mathrm{eV}$ at the interface between $4 \mathrm{at} \% \mathrm{Sb}: \mathrm{SnO}_{2}$ and $\mathrm{TiO}_{2}$ [11]. The diagram shows the electron transfer from the $\mathrm{SnO}_{2}$ to $\mathrm{TiO}_{2}$ that occurs due to the higher electron affinity of the $\mathrm{TiO}_{2}[18,20]$. This electron transfer takes place during the formation of the junction, as the equilibrium condition (Fermi level equality of both sides) is being reached, as seen in Fig. 6(a). Under photo-excitation the transfer of electrons from $\mathrm{TiO}_{2}$ to $\mathrm{SnO}_{2}$ may also occur, but it may be limited due to the potential barrier at their interface. The higher concentration of electrons on the $\mathrm{TiO}_{2}$ exposed surface increases the number of adsorption centers for gas molecules. The atmosphere with more gas molecules captures the superficial charges at a faster rate, which reduces more quickly the current $[11,44]$, as shown in Fig. 5. This adsorption process stops probably by the shielding of the sample surface by the adsorbed molecules that occupy all the surface sites and do not allow further molecule adsorption. Therefore, at the first 20 s of current-decay the charge trapping related to intrabandgap defects present in the sample determines the gas adsorption and sample conductivity.

In order to evaluate the temperature dependency of the sample resistance under gas adsorption, a different bias voltage was applied with $10^{-3}$ torr of pressure and room atmosphere condition. The results are shown in Fig. 7(a) for low pressure atmosphere, and in Fig. 7(b) for room atmosphere. One can notice that the resistance increases significantly when under room atmosphere, in all evaluated temperatures, for instance at $390 \mathrm{~K}$ the electrical resistances are $2 \mathrm{M} \Omega$ and $75 \mathrm{M} \Omega$ under vacuum and room atmospheres, respectively, as can be seen in Fig. 7(c). The resistance at room atmosphere is about 40 times higher due to the adsorbed $\mathrm{O}_{2}$ molecules that contribute directly to the reduction of free electrons in the semiconductor. At $\mathrm{T}=330 \mathrm{~K}$ the resistance under room atmosphere increases 30 times compared to vacuum condition, which implies that the raise of free electrons in the semiconductor at higher temperatures $(390 \mathrm{~K}$ ) also increases the adsorption sites on its surface, showing higher resistance variation when the atmosphere changes. As this investigated temperature is lower than the temperature for
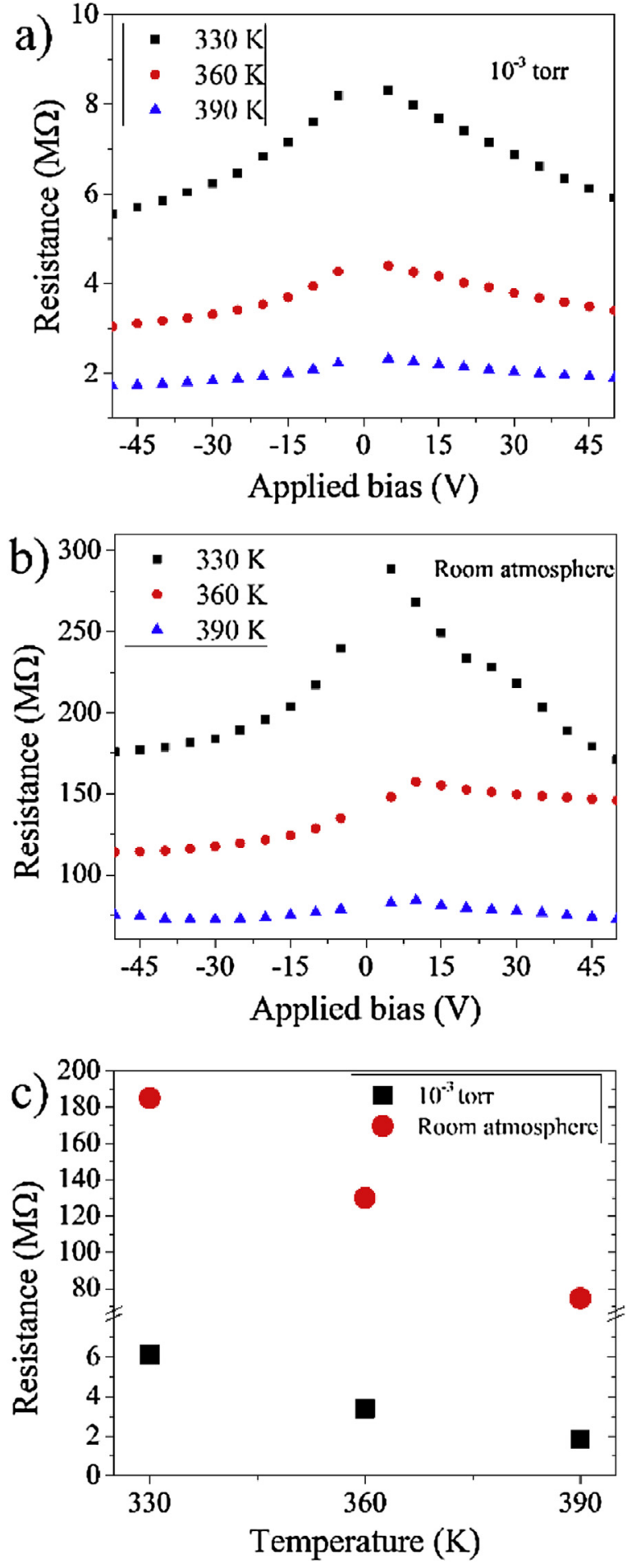

Fig. 7. Resistance as function of the applied bias voltage at different temperatures under (a) $10^{-3}$ torr, and under (b) room atmosphere. (c) A comparison of the resistances (average) at different temperatures and atmospheres presented in figures (a) and (b).

gas desorption from the $\mathrm{TiO}_{2}$ surface, that is around $410 \mathrm{~K}[24,26]$, this is the temperature that the device may be operated with better performance.

\section{Conclusion}

The investigation presented in this work showed that the formation of the heterostructure of $\mathrm{TiO}_{2}$ with $4 \mathrm{at} \% \mathrm{Sb}: \mathrm{SnO}_{2}$, is promising 
to gas sensors devices. The architecture with the $\mathrm{TiO}_{2}$ semiconducting layer exposed to atmosphere gases shows higher gas sensitivity when operating under UV light.These results are attributed to the electron transfer from the $\mathrm{SnO}_{2}$ to the $\mathrm{TiO}_{2}$ layer at junction formation, and under light irradiation, due to the further increase of electrons in the titanium oxide film. This charge transfer enhances the gas sensing mechanism through the larger electron capture by adsorbed molecules, which are responsible for the large electrical current variation in the devices under different atmospheres.

The results from the $\mathrm{Sb}: \mathrm{SnO}_{2}: \mathrm{Sb} / \mathrm{TiO}_{2}$ based sensors are promising concerning the functionality of the heterostructure and its low-cost obtaining method. The improvement of gas-sensitivity by using UV-light along the gas detection shows this material can operate at low temperature range $\left(30-120^{\circ} \mathrm{C}\right)$, being able to replace existing devices that operate at higher temperatures $\left(300-500^{\circ} \mathrm{C}\right)$.

\section{Acknowledgements}

The authors acknowledge Professor José Humberto D. da Silva for support with transmittance measurements, Professor Dayse Iara dos Santos for support with XRD measurements, which were performed at Multiuser Lab. at UNESP/DF Campus Bauru, and to PNPD/CAPES and CNPq for financial support.

\section{References}

[1] C. Garzella, E. Comini, E. Tempesti, C. Frigeri, G. Sberveglieri, $\mathrm{TiO}_{2}$ thin films by a novel sol-gel processing for gas sensor applications, Sens. Actuators B Chem. 68 (2000) 189-196.

[2] X. Chen, S.S. Mao, Titanium dioxide nanomaterials: synthesis, properties, modifications and applications, Chem. Rev. 107 (2007) 2891-2959.

[3] S. Luo, J. Fan, W. Liu, M. Zhang, Z. Song, C. Lin, X. Wu, P.K. Chu, Synthesis and low-temperature photoluminescence properties of $\mathrm{SnO}_{2}$ nanowires and nanobelts, Nanotechnology 17 (2006) 1695-1699.

[4] J. Saura, Gas-sensing properties of $\mathrm{SnO}_{2}$ pyrolytic films subjected to ultraviolet radiation, Sens. Actuators B Chem. 17 (1994) 211-214.

[5] A.S. Chizhov, M.N. Rumyantseva, R.B. Vasiliev, D.G. Filatova, K.A. Drozdov, I.V. Krylov, A.M. Abakumov, A.M. Gaskov, Visible light activated room temperature gas sensors based on nanocrystalline $\mathrm{ZnO}$ sensitized with CdSe quantum dots, Sens. Actuators B Chem. 205 (2014) 305-312.

[6] S. Mishra, C. Ghanshyam, N. Ram, R.P. Bajpai, R.K. Bedi, Detection mechanism of metal oxide gas sensor under UV radiation, Sens. Actuators B Chem. 97 (2004) 387-390.

[7] E. Comini, L. Ottini, G. Faglia, G. Sberveglieri, $\mathrm{SnO}_{2}$ RGTO UV activation for $\mathrm{CO}$ monitoring, IEEE Sens. J. 4 (2004) 17-20.

[8] J. Gong, Y. Li, X. Chai, Z. Hu, Y. And, Deng, UV-Light -activated ZnO Fibres for organic gas sensing at room temperature, J. Phys. Chem. C 114 (2010).

[9] J.D. Prades, R. Jimenez-Diaz, F. Hernandez-Ramirez, S. Barth, A. Cirera, A. Romano-Rodriguez, S. Mathur, J.R. Morante, Equivalence between thermal and room temperature UV light-modulated responses of gas sensors based on individual $\mathrm{SnO}_{2}$ nanowires, Sens. Actuators B Chem. 140 (2009) 337-341.

[10] H.-C. Lee, W.-S. Hwang, Substrate effects on the oxygen gas sensing properties of $\mathrm{SnO}_{2} / \mathrm{TiO}_{2}$ thin films, Appl. Surf. Sci. 253 (2006) 1889-1897.

[11] E.A. Floriano, L.V.A. Scalvi, M.J. Saeki, J.R. Sambrano, Preparation of $\mathrm{TiO}_{2} / \mathrm{SnO}_{2}$ thin films by sol-gel method and periodic B3LyP simulations, Phys. Chem. A 118 (2014) 5857-5865.

[12] X. Ren, H. Fan, J. Ma, C. Wang, M. Zhang, N. Zhao, Hierarchical $\mathrm{Co}_{3} \mathrm{O}_{4} / \mathrm{PANI}$ hollow nanocages: synthesis and application for electrode materials of supercapacitors, Appl. Surf. Sci. 441 (2018) 194-203.

[13] M. Zhang, H. Fan, N. Zhao, H. Peng, X. Ren, W. Wang, H. Li, G. Chen, Y. Zhu, X Jiang, $\mathrm{P}$. Wu, 3D hierarchical $\mathrm{CoWO}_{4} / \mathrm{Co}_{3} \mathrm{O}_{4}$ nanowire arrays for asymmetric supercapacitors with high energy density, Chem. Eng. J. 347 (2018) 291-300.

[14] H. Tian, H. Fan, J. Ma, Z. Liu, L. Ma, S. Lei, J. Fang, C. Long, Pt-decorated zinc oxide nanorod arrays with graphitic carbon nitride nanosheets for highly efficient dual-functional gas sensing, J. Hazard. Mater. 341 (2018) 102-111

[15] L. Ma, H. Fan, H. Tian, J. Fang, X. Qian, The $\mathrm{n}-\mathrm{ZnO} / \mathrm{n}-\mathrm{In}_{2} \mathrm{O}_{3}$ heterojunction formed by a surface-modification and their potential barrier-control in methanal gas sensing, Sens. Actuators B Chem. 222 (2016) 508-516.

[16] O. Lupan, N. Wolff, V. Postica, T. Braniste, I. Paulowicz, V. Hrkac, Y.K. Mishra, I. Tiginyanu, L. Kienle, R. Adelung, Properties of a single $\mathrm{SnO}_{2}: \mathrm{Zn}_{2} \mathrm{SnO}_{4}-$ Functionalized nanowire based nanosensor, Ceram. Int. 44 (2018) 4859-4867.

[17] O. Lupan, V. Cretu, V. Postica, N. Ababii, O. Polonskyi, V. Kaidas, F. Schütt, Y.K. Mishra, E. Monaico, I. Tiginyanu, V. Sontea, T. Strunskus, F. Faupel, R. Adelung, Enhanced ethanol vapour sensing performances of copper oxide nanocrystals with mixed phases, Sens. Actuators B Chem. 224 (2016) 434-448.

[18] A.G. Milnes, D.L. Feucht, Heterojunctions and Metal Semiconductor Junctions, Acad. Press, 1972, pp. 419.
[19] W.G. Oldham, A.G. Milnes, n-n Semiconductor heterojunctions, Solid. Electron. 6 (1963) 121-132.

[20] D.O. Scanlon, C.W. Dunnill, J. Buckeridge, S.A. Shevlin, A.J. Logsdail, S.M. Woodley, C. Richard, A. Catlow, M.J. Powell, R.G. Palgrave, I.P. Parkin, G.W. Watson, T.W. Keal, P. Sherwood, A. Walsh, A.A. Sokol, Band alignment of rutile and anatase $\mathrm{TiO}_{2}$, Nat. Mater. 12 (2013) 798-801.

[21] O. Carp, C.L. Huisman, A. Reller, Photoinduced reactivity of titanium dioxide, Prog. Solid State Chem. 32 (2004) 33-177.

[22] K. Kalyanasundaram, Titânia in diverse forms as substrates, in: Dye. Sol. Cells, 1st ed., EPFL Press, 2010, pp. 47.

[23] J. Nisar, Z. Topalian, A. De Sarkar, L. Osterlund, R. Ahuja, $\mathrm{TiO}_{2}$-based gas sensor: a possible application to $\mathrm{SO}_{2}$, ACS Appl. Mater. Interfaces 5 (2013) 8516-8522.

[24] B. Zhang, J.K. Johnson, Properties of weakly bound molecular oxygen on the rutile $\mathrm{TiO}_{2}$ (110) surface from density functional theory, J. Phys. Chem. C 117 (2013) 17151-17158.

[25] W. Zeng, T. Liu, Z. Wang, Impact of Nb doping on gas-sensing performance of $\mathrm{TiO}_{2}$ thick-film sensors, Sens. Actuators, B Chem. 166-167 (2012) 141-149.

[26] M.A. Henderson, W.S. Epling, C.L. Perkins, C.H.F. Peden, U. Diebold, Interaction of molecular oxygen with the vacuum-annealed $\mathrm{TiO}_{2}$ (110) surface: molecular and dissociative channels, J. Phys. Chem. B 103 (1999) 5328-5337.

[27] M.H. Boratto, L.V. de, A. Scalvi, J.L.B. Maciel Jr, M.J. Saeki, E.A. Floriano, Heterojunction between $\mathrm{Al}_{2} \mathrm{O}_{3}$ and $\mathrm{SnO}_{2}$ thin films for application in transparent FET, Mater. Res. 17 (2014) 1420-1426.

[28] G. Sanon, R. Rup, A. Mansingh, Band-gap narrowing and band structure in degenerate tin oxide $\left(\mathrm{SnO}_{2}\right)$ films, Phys. Rev. B 44 (1991) 5672-5680.

[29] R. Rai, T.D. Senguttuvan, S.T. Lakshmikumar, Study of the electronic and optical bonding properties of doped $\mathrm{SnO}_{2}$, Comput. Mater. Sci. 37 (2006) 15-19.

[30] E.A. Floriano, L.V.A. Scalvi, J.R. Sambrano, A. De Andrade, Decay of photo-induced conductivity in Sb-doped $\mathrm{SnO}_{2}$ thin films, using monochromatic light of about bandgap energy, Appl. Surf. Sci. 267 (2013) $164-168$.

[31] V. Geraldo, L.V.A. Scalvi, P.N. Lisboa-Filho, C. Morilla-Santos, Drude's model calculation rule on electrical transport in Sb-doped $\mathrm{SnO}_{2}$ thin films, deposited via sol-gel, J. Phys. Chem. Solids 67 (2006) 1410-1415.

[32] G. Oskam, A. Nellore, R.L. Penn, P.C. Searson, The growth kinetics of $\mathrm{TiO}_{2}$ nanoparticles from titanium(IV) alkoxide at high water/ titanium ratio, J. Phys. Chem. B 107 (2003) 1734-1738.

[33] R. de, A. Ramos Jr, M.H. Boratto, M.S. Li, L.V. de, A. Scalvi, Emission properties related to distinct phases of sol-gel dip-coating titanium dioxide, and carrier photo-excitation in different energy ranges, Mater. Res. 20 (2017) 866-873.

[34] M.H. Boratto, L.V.A. Scalvi, L.V. Goncharova, G. Fanchini, Effects of solution history on sol-gel processed tin-oxide thin-film transistors, J. Am. Ceram. Soc. 99 (2016) 4000-4006.

[35] M.H. Boratto, R.A. Ramos, L.V.A. Scalvi, Investigation of sensing properties of sol-gel processed 4 at\% $\mathrm{Sb}: \mathrm{SnO}_{2} / \mathrm{TiO}_{2}$ thin films, J. Mater. Sci. Mater. Electron. (2017) 467-473

[36] K. Ding, Z. Miao, B. Hu, G. An, Z. Sun, B. Han, Z. Liu, Study on the anatase to rutile phase transformation and controlled synthesis of rutile nanocrystals with the assistance of ionic liquid, Langmuir 26 (2010) 10294-10302.

[37] J. Zhang, Q. Xu, M. Li, Z. Feng, C. Li, UV Raman spectroscopic study on $\mathrm{TiO}_{2}$. II. Effect of nanoparticle size on the Outer/Inner phase transformations, J. Phys. Chem. C. 113 (2009) 1698-1704.

[38] A. Beltrán, J. Andrés, J.R. Sambrano, E. Longo, Density functional theory study on the structural and electronic properties of low index rutile surfaces for $\mathrm{TiO}_{2} / \mathrm{SnO}_{2} / \mathrm{TiO}_{2}$ and $\mathrm{SnO}_{2} / \mathrm{TiO}_{2} / \mathrm{SnO}_{2}$ composite systems, J. Phys. Chem. A 112 (2008) 8943-8952.

[39] M.H. Boratto, R.A. Ramos, M. Congiu, C.F.O. Graeff, L.V.A. Scalvi, Memristive behavior of the $\mathrm{SnO}_{2} / \mathrm{TiO}_{2}$ interface deposited by sol-gel, Appl. Surf. Sci. (2017) 410.

[40] S.M. SZE, Modern Semiconductor Device Physics, John Wiley, 1998.

[41] R.G. Breckenridge, W.R. Hosler, Electrical properties of titanium dioxide semiconductors, Phys. Rev. 91 (1953) 793-802.

[42] H. Tang, R. Sanjines̀, P.E. Schmid, F. Lé vy, Ellectrical and optical properties of $\mathrm{TiO}_{2}$ anatase thin films, J. Appl. Phys. 75 (1994) 2042.

[43] L.P. Ravaro, D.I. dos Santos, L.V.A. Scalvi, Effect of pH of colloidal suspension on crystallization and activation energy of deep levels in $\mathrm{SnO}_{2}$ thin films obtained via sol-gel, J. Phys. Chem. Solids 70 (2009) 1312-1316.

[44] E.A. Morais, L.V.A. Scalvi, Electron trapping of laser-induced carriers in Er-doped $\mathrm{SnO}_{2}$ thin films, J. Eur. Ceram. Soc. 27 (2007) 3803-3806.

[45] E.A. Morais, L.V.A. Scalvi, A.A. Cavalheiro, A. Tabata, J.B.B. Oliveira, Rare earth centers properties and electron trapping in $\mathrm{SnO}_{2}$ thin films produced by sol-gel route, J. Non. Solids 354 (2008) 4840-4845.

[46] T.W. Dobson, L.V.A. Scalvi, J.F. Wager, Transient decay of persistent photoconductivity in $\mathrm{Al}_{0.3} \mathrm{Ga}_{0.7}$ As, J. Appl. Phys. 68 (1990) 601-605.

[47] E.A. Morais, L.V.A. Scalvi, A. Tabata, J.B.B. De Oliveira, S.J.L. Ribeiro, Photoluminescence of $\mathrm{Eu}^{3+}$ ion in $\mathrm{SnO}_{2}$ obtained by sol-gel, J. Mater. Sci. 43 (2008) 345-349.

[48] N. Martin, A. Besnard, F. Sthal, F. Vaz, C. Nouveau, The contribution of grain boundary barriers to the electrical conductivity of titanium oxide thin films, Appl. Phys. Lett. 93 (2008), 064102.

[49] P.M. Mooney, G.A. Northrop, T.N. Morgan, H.G. Grimmeis, Evidence for large lattice relaxation at the DX center in Si-doped $\mathrm{Al}_{\mathrm{x}} \mathrm{Ga}_{1-\mathrm{x}} \mathrm{As}$, Phys. Rev. B 37 (1988) 8298-8307

[50] W. Göpel, G. Rocker, R. Feierabend, Intrinsic defects of $\mathrm{TiO}_{2}(110)$ : Interaction with chemisorbed $\mathrm{O}_{2}, \mathrm{H}_{2}, \mathrm{CO}$, and $\mathrm{CO}_{2}$, Phys. Rev. B 28 (1983) 3427-3438. 
[51] F.T. Mackenzie, J.A. Mackenzie, Our Changing Planet, Prentice Hall, Upper Sadle River, NJ, 1995.

[52] M.N. Islam, M.O. Hakim, Electron affinity and work function of polycrystalline $\mathrm{SnO}_{2}$ thin film, J. Mater. Sci. Lett. 5 (1986) 63-65.

[53] A. Borodin, M. Reichling, Characterizing $\mathrm{TiO}_{2}$ (110) surface states by their work function, Phys. Chem. Chem. Phys. 13 (2011) 15442-15447.

[54] Y.W. Chung, W.J. Lo, G.A. Somorjai, Low energy Electron diffraction and Electron spectroscopy studies of the clean (110) and (100) titanium dioxide (Rutile) crystal surfaces, Surf. Sci. 64 (1977) 588-602.

[55] S. Szuber, G. Czempik, R. Larciprete, B. Adamowicz, The comparative XPS and PYS studies of $\mathrm{SnO}$ thin films prepared by 2 L-CVD technique and exposed to oxygen and hydrogen, Sens. Actuators B Chem. 70 (2000) 177-181.

[56] P.A. Cox, R.G. Egdell, C. Harding, W.R. Patterson, P.J. Tavener, Surface properties of antimony doped tin(IV) oxide: a study by electron spectroscopy, Surf. Sci. 123 (1982) 179-203.

[57] J.M. Themlin, R. Sporken, J. Darville, R. Caudano, J.M. Gilles Resonant-photoemission study of $\mathrm{Sno}_{2}$. Cationic origin of the defect band-gay states, Phys. Rev. B 42 (1990) 914-925.

\section{Biographies}

R. A. Ramos Jr. graduated in Physics (2015) and has Masters in Materials Science and Technology (2018) by the São Paulo State University Professor Júlio de Mesquita Filho. During his Master's, Ramos Jr. studied thin films of titanium and tin dioxides for gas sensing applications. Currently Ramos Jr. is PhD student in Materials Science and Technology at the São Paulo State University and works with semiconductor thin films aiming non-volatile memories.
M. H. Boratto graduated in Physics and has Master's and Ph.D. in Materials Science and Technology by the São Paulo State University (UNESP). During his Ph.D. Boratto participated as researcher at the University of Western Ontario - Canada. Migue is currently a PostDoc at the Physics Department of the Federal University of Sant Catarina (UFSC). His main works involve the development and study of semiconductors $\left(\mathrm{TiO}_{2}\right.$ and $\left.\mathrm{SnO}_{2}\right)$ and dielectric $\left(\mathrm{Al}_{2} \mathrm{O}_{3}, \mathrm{ZrO}_{2}\right)$ materials for the obtainment of electronic devices such as transistors, capacitors, memristors, and gas sensors.

L. V. A. Scalvi: Chemical Engineer: Federal University of São Carlos (Brazil-1983), Ph.D. Applied Physics: University of São Paulo (Brazil-1991). Research Associate: Oregon State University, U.S.A. (06/1988-06/1990); Visiting Researcher: Laboratory Synchrotron SOLEIL, France (1-4/2009). Director of Meteorological Research Institute, Brazil (11/2011-5/2013). Coordinator of Materials Science and Technology graduate Program (6/2013-10/2017). Professor at State University of São Paulo for 25 years. Experience: Solid State Physics and Materials Science, with about 90 publications. Presently working in: oxide semiconductors, heterostructures, thin films, graphene, electrical transport. Recently participated as UNESP delegate in the First Meeting of BRICS Working Group on Materials Science and Nanotechnologies (Ekaterinburg, Russia, 2017). 